\title{
Karbon-Fiber Plaka Donatılı Traverslerin, B70-Tipi Öngerilmeli Beton Traverslerle Karşılaştırmalı İncelenmesi
}

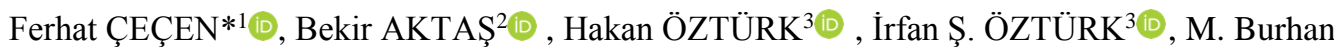 \\ NAVDAR ${ }^{3}$
}

\author{
${ }^{1}$ TCDD Sivas Beton Travers Fabrikast Müdürlügü̈, Sivas, Türkiye \\ ${ }^{2}$ Erciyes Üniversitesi, Mühendislik Fakültesi, İnşaat Mühendisliği Bölümü, Kayseri, Türkiye \\ ${ }^{3}$ Sakarya Üniversitesi, Mühendislik Fakültesi, İnşaat Mühendisliği Bölümü, Sakarya, Türkiye
}

*ferhatcecen@tcdd.gov.tr

(Alınış/Received: 26.11.2021, Kabul/Accepted: 03.01.2022, Yayımlama/Published: 31.01.2022)

Öz: Bu çalışma kapsamında, yerli karbon fiber takviyeli poliüretan plakalar ile donatılandırılmış beton traverslerin merkez negatif eğilme performansı, öngerilmeli B70 tipi traverslerle karşılaştırmalı yürütülen deneyler ile araștırılmıştır. Yapılan testler sonucunda, yeni tip traverslerin yorulma esaslı dizayn yükünün, B70 tipi öngerilmeli traverslerin 2 katına ulaşan oranda daha yüksek sonuçlandığı görülmüsştür. Ayrıca yeni tip traverslerde herhangi bir öngerilme kuvveti veya etriye kullanılmamasına rağmen, B70 tipi öngerilmeli traverslerin kırılma yükünün üzerindeki yük değerlerinde dahi, meydana gelen çatlak genişliklerinin halen 0,05 mm'nin altında kaldığı görülmüştür. Bu avantajlar, raylı sistemlerde ekartman açıklıklarının korunarak deray ve kazaların önlenmesi ve travers servis ömrünün artırılması adına oldukça önemlidir.

Anahtar kelimeler: Karbon fiber takviyeli poliüretan, CFRP, beton travers, LCR tipi travers, YKY çevrimi

\section{Comparative Investigation of Carbon-Fiber Laminate Reinforced Sleepers with B70-Type Prestressed Concrete Sleepers}

\begin{abstract}
In this study, the center negative bending performance of concrete sleepers reinforced with domestic carbon fiber reinforced polyurethane laminates is investigated by comparative experiments with prestressed B70 type concrete sleepers. According to the test results, the fatigue-based design load of the new type of sleepers is two times higher than the B70 type prestressed sleepers. In addition, although no prestressing force or stirrups are used in the new type of sleepers, the crack widths that occur are still below $0.05 \mathrm{~mm}$, even at the load values above the breaking load of the B70 type prestressed sleepers. These advantages are significant to prevent derailment and accidents by protecting rail gauge openings and increasing the service life of the sleeper.
\end{abstract}

Keywords: Carbon fiber reinforced polyurethane, CFRP, concrete sleeper, LCR type sleeper, LUR cycle

\section{Giriş}

Günümüzde şehirler ve ülkeler arası yük ve yolcu taşımacılığında en yaygın tercih edilen raylı ulaşım sistemi balastlı demiryollarıdır. Balastlı demiryollarında geçmişte ahşap ve çelik traversler yaygın olarak kullanılmış olsa da, günümüzde en çok tercih edilen travers tipi betonarme traverslerdir (yaygin tabiriyle beton traversler) [1]. Beton traversler, genel anlamda, geometrik şekillerine ve donatılarının durumuna göre iki kategoriye ayrılmaktadır. Geometrik olarak, Şekil 1.a'da görüldügüü üzere tek parça halinde üretilen traversler için "yekpare" beton travers (monoblock concrete sleeper) tabiri, Şekil 1.b'de görüldüğü üzere iki eș parça halindeki betonarme kütlenin çelik profillerle bağlandığı tip için ise "ikiz-blok" beton travers (twin-block concrete sleeper, traverse bibloc) tabiri kullanılmaktadır. Beton traversler donatı bakımından ise öngerilmeli ve öngerilmesiz olarak iki kategoriye ayrılmaktadır. Öngerilmeli beton traversler (prestressed concrete sleepers), donatıların tamamı veya bir kısmına öngerilme kuvveti uygulanarak üretilmektedir. Öngerilmesiz beton traversler (non-prestressed concrete sleepers, 
reinforced concrete sleepers) ise, Şekil 1.b'de görüldüğü üzere, boyuna ve enine (etriye) istikamette ve bazı modellerde spiral halinde öngerilmesiz donatılar kullanılarak üretilmektedir. Günümüzde beton traverslerin tamamına yakınında hammaddesi çelik olan donatılar kullanılmakta olup, öngerilmeli tiplerde özel HTS tipi (High Tensile Strength) yüksek çekme dayanımına sahip öngerilme çubukları veya halatları kullanılmaktadır. Şekil 2'de söz konusu HTS tipi çelik öngerilme çubukları ve öngerilme işlemi için ihtiyaç duyulan ankraj plaka ve somunlarından örnekler sunulmaktadır. Tüm bu tipler içerisinde ise Ülkemizde ve dünyada en yaygın kullanılan tip, öngerilmeli yekpare beton traverslerdir [2, 3]. Öngerilmeli beton traverslerin birçok avantajı söz konusudur. Bu avantajlardan en ön planda olanı; ilk çatlak oluşma yükünün öngerilmesiz rakiplerine göre çok daha yüksek olması ve belirli bir yük değerine ve tekrarına kadar oluşan çatlakları kapatma yeteneğidir $[4,5]$. Bu tip traversler ayrıca öngerilme kuvveti sayesinde daha düşük hammadde $[2,4]$ ve daha az donatı $[6,7]$ kullanımı sağlamaktadır. Ancak literatürde, söz konusu öngerilmeli betonarme traverslerin birçok dezavantajları da yer almaktadır. Bunlardan bazıları; zayıf zemin şartlarında (sönümleme performansının düşüklüğü nedeniyle) kullanılamaması [4, 7], balast gerilimlerinde artışa neden olması [4], ahşap, çelik ve kompozit traverslere göre daha ağır olduğu için makineli bakım gerektirmesi [5, 6], enine istikamette donatı içermemesi nedeniyle boyuna çatlaklara açık olması $[4,8]$, düşük esnekliği nedeniyle elastik bağlantı ekipmanına ihtiyaç duyulması [9], elektriksel iletkenlik riski taşıdığından özel yalıtım malzemelerine ihtiyaç duyulması [5], yüksek dayanımlı beton kullanım zorunluluğu nedeniyle düktilitede düşüş̧e neden olmas1 [10], düşük sönümleme performans1 ve rezonans zafiyeti [3, 4, 11-13], çelik donatıların korozyon riski taşıması [2, 13, 14], yüksek karbondioksit emisyonuna neden olmas1 [7, 15], düşük yorulma dayanımına sahip olması $[4,13$, $14,16,17]$ ve çeşitli iklimsel etkiler altında öngerilme kapasitesinin düşmesi [13, 18-22] olarak sayılabilir. Ayrıca Ülkemiz için söz konusu olan bir diğer dezavantaj, öngerilmeli beton travers üretiminde kullanılan HTS tipi çelik çubukların hammaddesinin çoğunlukla ithal edilmesidir. Bu avantaj ve dezavantaj döngüsü içerisinde, tasarımı esas alan yapı mühendisleri öngerilmeli traverslerin gereğinden fazla yüksek kapasite ile üretildiğine dikkat çekmek isterken, sahada görevli bakım mühendisleri ise öngerilmeli betonarme traverslerin dizayn ömrünün erken aşamasında deforme olmalarından yakınmaktadır [3, 23-27]. Ancak raylı ulaşım sistemlerinin geçmişten çok daha yüksek hızlar, dingil yükleri ve işletim sıklığı ile karşı karşıya olduğu ve klasik beton traverslerin birçoğunun planlanan 40-50 y1llık dizayn ömrüne ulaşamadan değiştirilmek zorunda kaldığ 1 istatiksel bir gerçektir [1, 28, 29]. Buna ilaveten, doğru bir şekilde dizayn edilmemiş traversler, hem kendilerinin hem de diğer tüm demiryolu bileşenlerinin erken deforme olmasına neden olmaktadır [28]. Bu durum ise, tüm dünyada demiryolu bakım işlemlerinin maliyetini artırmaktadır $[11,28]$. Sonuç olarak literatürdeki birçok çalışmada, demiryolu traverslerinin dizayn metotlarında önemli değişimler yapılması istenmektedir [1, 9, 3035]. Bu yüzden günümüze kadar dünyada birçok ülkede yüzlerce çeşit beton travers modeli geliştirilmiş ve halen geliştirilmeye devam etmektedir. Bu çalışmada konu edilen yeni tip traverslerde ise, dünyada mevcut beton traverslerde kullanılan çelik donatılar yerine, yerli lamine karbon fiber takviyeli poliüretan plakalar (L-CFRPU), uygun ebatlarda kesilerek ve kumlama yapılarak, beton donatısı olarak kullanılmışıtı. Literatürde belirtildiği üzere, karbon fiber takviyeli polimer (CFRP) ürünler; klor, sülfat, korozyon, nem, alkali ve asit dâhil, zararlı çevresel etkilere karş1 çok yüksek dayanıklılığa sahiptir [36]. Ayrıca CFRP ürünlerin elastisite modülü, çelik donatılarla benzer ve diğer fiber takviyeli polimer ürünlerin en az 2 katıdır [37]. Bu özellikler, yüksek tekrarlı dinamik yüklerin ve zararlı çevresel etkilerin söz konusu olduğu ve iki ray arasındaki mesafe olan ekartman açıklığının büyük önem arz ettiği raylı ulaşım sistemleri için büyük fayda sağlamaktadır. Önceki çalışmalarımızda bu yeni tip traverslerin standartlarda istenilen; kademeli artan yükleme-kaldırma-yeniden yükleme (YKY) esaslı ray mesnedinde pozitif moment tayini deneyleri yapılmış, bu zorunlu testlerin akabinde, yüksek hız ve şiddete sahip tekrarlı darbe testleri ve sönümleme performansı ile rezonans direncinin incelendiği modal analizler de uygulanmıştır $[1,3,38,39,40]$. Test ve analiz sonuçlarına göre, yeni tip traversler Paris-Londra yüksek hızlı demiryolu hattında da kullanılmış olan öngerilmesiz Vagneux U3 tipi modern betonarme traverslere göre $\% 180$ daha yüksek kalıcı çatlak başlangıç yükü kapasitesine 
ve \%128 daha yüksek kırılma yükü kapasitesine erişmiştir. Ülkemizde ve dünyada yüksek hızlı demiryolu hatları dâhil yaygın bir şekilde kullanılan öngerilmeli B70 tipi betonarme traverslere göre ise; \%29 daha yüksek kalıcı çatlak başlangıç yükü kapasitesine, \%5 daha yüksek kırılma yükü kapasitesine ve $\% 58$ daha yüksek sönümleme performansına erişmiştir. Şekil 3 'te yeni tip traverslerin üretimi esnasında alınan görseller sunulmaktadır. Görüldüğü üzere, yeni tip LCFRPU donatılı traverslerin belirtilen performans faydalarının yanı sıra, öngerilmesiz ve etriyesiz üretim yöntemi sayesinde, büyük bir üretim kolaylı̆̆ı ve ekonomisi de mevcuttur. Oysaki; öngerilmeli beton travers üretiminde (Şekil 1.a ve 2) erken yüksek beton dayanımı gerektiği gibi, donatı montaj, ankrajlama, öngerilme uygulama, enjeksiyon-izolasyon gibi birçok iş kalemi gerekmektedir. Öngerilmesiz beton traverslerde ise (Şekil 1.b) birçok etriye, spiral donatı ve ara bağlantı çubuğu üretimi ve montajı, önemli miktarda hammadde, enerji ve zaman kaybı söz konusudur.

a)

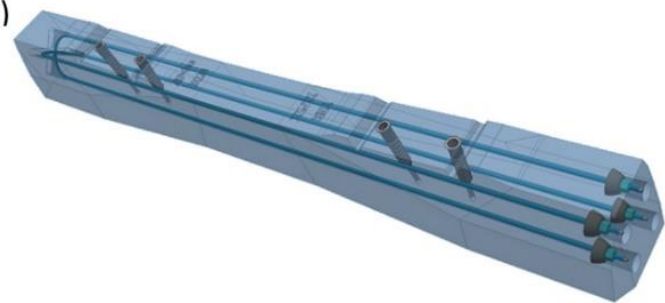

b)

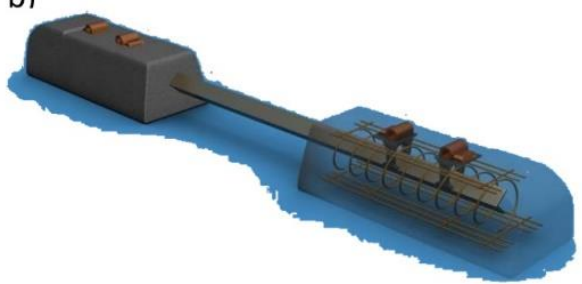

Şekil 1. Yekpare beton travers [41] ve ikiz-blok beton traverslerin [42] donatı ve ankraj planları
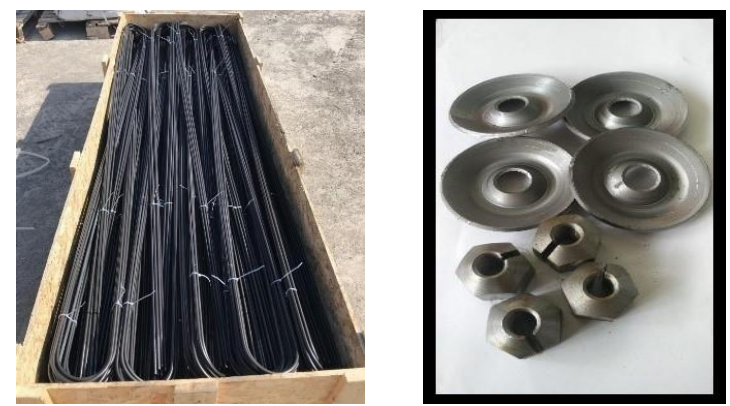

Şekil 2. B70 tipi standart öngerilmeli betonarme demiryolu traverslerinin üretimi esnasında kullanılan ithal hammaddeli öngerme çelikleri ile ankraj işleminde kullanılan plaka ve somunlar
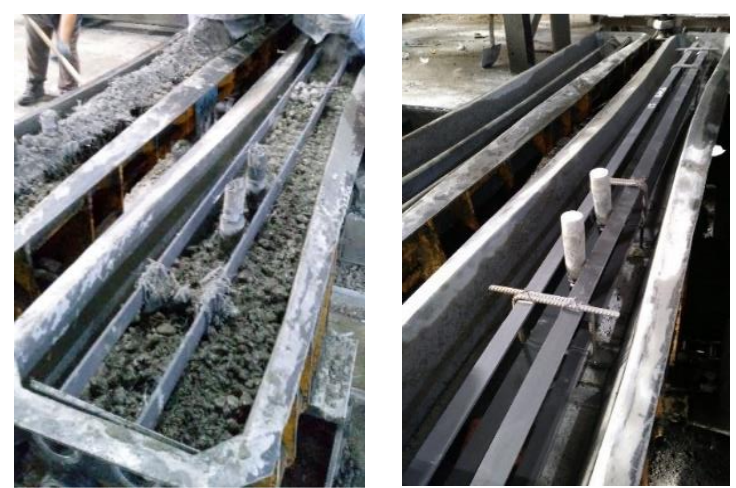

Şekil 3. Yeni geliştirilen 30-VRTC-SND (sol) ve 30-SND tipi (sağ) L-CFRPU donatılı betonarme demiryolu traverslerinin üretimleri esnasında alınan örnek görseller

Belirtilen avantaj ve dezavantajlar haricinde, modern demiryolları için düşük bakım ihtiyacı bir diğer önemli konudur. Çünkü modern demiryolu işletmeciliğinde, tren seferleri çok sık aralıklarla yapılmakta olup, Şekil 4'te örneği verildiği üzere, bakım ve tamirat işlemleri için ayrılabilecek süreler, geceleri birkaç saatle kısıtlıdır. Bu yüzden dünya genelinde fiili servis ömrü daha uzun 
ve diğer demiryolu bileșenlerini de koruyan sönümleme performansı ve rezonans direnci yüksek travers modelleri geliştirilmeye çalışılmaktadır.

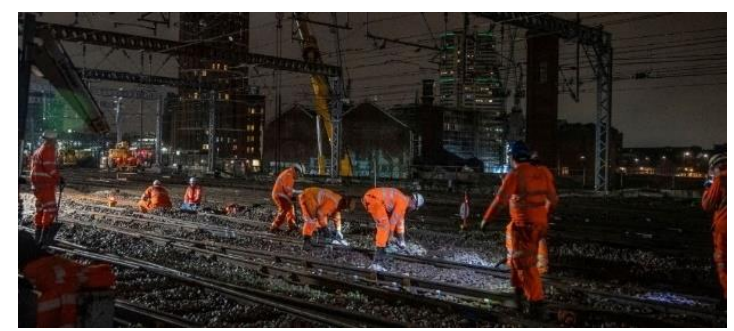

Şekil 4. Modern demiryollarında bakım işlemlerinin geceleri yapılma ihtiyacına dair bir örnek [43]

Son olarak, mevcut öngerilmeli beton traverslerde kullanılan HTS tipi öngerilme çubuklarının hammaddesi hâlihazırda ülkemizde çoğunlukla ithal edilmekte olup, 1 adet traversteki maliyeti yaklaşık 135 TL'dir. Yeni geliştirilen L-CFRPU donatılı traverslerin üretiminde de kullanılan karbon fiber malzemeler, dünyada yalnızca 9-10 ülkede üretilebilmekte olup, bunlardan biri Türkiye'dir. Günümüzde 1 adet travers için söz konusu L-CFRPU plaka temini maliyeti, mevcut öngerilmeli beton traverslerde kullanılan çelik donatı maliyetinden \%23'e varan oranda daha düşüktür (2021 yılı için $105 \mathrm{TL} /$ travers). Bu maliyet avantaj1, yeni tip traverslerin öngerilmesiz ve etriyesiz kolay üretim şekliyle daha da artmaktadır. Yeni tip traverslerin, servis ömründe sağlayacağı artış ve demiryolu bakım ve işletimi esnasında sağlanacak tasarruflar ile mali avantaj kat kat artmaktadır. Günümüzde dünya genelinde en az 3 milyar travers kullanılmakta olup, bunların ise her yıl en az 150 milyon adedi erken deformasyonlar nedeniyle değiştirilmek zorunda kalmaktadır [15]. Dolayısıyla yeni tip traverslerin yüksek ticarileşme potansiyeli bulunmakta olup, hitap ettiği pazarın market hacmi oldukça büyüktür. Bu durum yerli madenlerin katma değerlerinin artırılması bağlamında da önem taşımaktadır.

\section{Metot}

Yeni geliştirilen L-CFRPU donatılı beton demiryolu traversleri, bugüne kadar yazarlar tarafindan gerçekleştirilen çeşitli çalışmalara $[1,3,38,39,40]$ konu olmuş ve yeni tip traverslerin ray mesnedinde YKY tipi pozitif moment tayini testleri, darbe testleri ve modal analizleri yapılarak dayanım ve sönümleme karakteristikleri mevcut travers tipleri ile karşılaştırmalı olarak ortaya konulmuştur. Ancak bu yeni tip traverslerin merkez (orta) noktasında, YKY tipi testler esnasında sergileyeceği performans, herhangi bir çalışmada incelenmemiştir. Çalışma kapsamında bu konu, TS EN 13230-2:2016 [44] standardında geçen, travers merkezinde negatif eğilme momenti tayini deneyleri ile araştırılmıştır. Testler esnasında mesnet açıklığı $(1,50 \mathrm{mt})$ ve yükleme hızı (yük kontrollü, $120 \mathrm{kN} / \mathrm{dk}$ ) standartta belirtildiği şekilde uygulanmıştır. Diğer detaylar standartta verilmektedir. Standart test metodunda bu çalışma için yapılan ilave ile her YKY adımı için, traverslerin artık (plastik) düşey yer değiştirme değerleri doğrusal değişken fark transformatörü (LVDT) ile kayda alınarak test grafikleri sunulmuştur. Test numunesi olarak L-CFRPU donatılı traversler 3 farklı donatı varyasyonu ile kullanılmış, ayrıca karşılaştırma numunesi olarak eşdeğer beton dayanımı ve kesit ölçülerine sahip, dünyada ve ülkemizde yaygın olarak kullanılan B70 tipi öngerilmeli beton traversler kullanılmıştır. 22-SND tipinde 4 adet $22 \mathrm{~mm}$ 'lik L-CFRPU plaka kumlanarak yatay vaziyette, 30-SND tipinde 4 adet $30 \mathrm{~mm}$ 'lik L-CFRPU plaka kumlanarak yatay vaziyette, 30-VRTC-SND tipinde 4 adet $30 \mathrm{~mm}$ 'lik L-CFRPU plaka kumlanarak dikey vaziyette kullanılmıştır. B70 tipi ve yeni tip traverslerin üretim aşamaları ve kullanılan malzemelerin karakteristik özellikleri, önceki çalışmalarda [1, 3, 38, 39, 40] sunulmuştur. Test sonuçları, B70 tipi traversler için; TS EN 13230-2:2016 [44] normuna göre UIC (Dünya Demiryolu Birliği) üyesi ülkelerce istenen şu kriterlerle karşılaştırılmıştır: a) Travers merkezinde yorulma esaslı dizayn yükünün $\left(\mathrm{Fc}_{\mathrm{o}}\right)$ en az $35 \mathrm{kN}$ olması. b) Travers merkezinde ilk çatlak başlangıç yükünün $\left(\mathrm{Fc}_{\mathrm{r}}\right)$, $\mathrm{Fc}$ o n $(\mathrm{kN})$ değerinden yüksek olması. c) Travers servis ömrü içerisinde yalnızca birkaç defa görülmesine izin verilen istisnai darbe yükünün $\left(\mathrm{Fc}{ }_{0.05}\right)$ en az $65 \mathrm{kN}$ olmas1. d) Travers servis 
ömrü boyunca 1 defa görülmesine izin verilen kırılma yükünün $\left(\mathrm{Fc}_{\mathrm{b}}\right)$ en az $90 \mathrm{kN}$ olmas1. Belirtilen bu limitler öngerilmeli traversler için geçerli olup, öngerilmesiz traverslerin orta noktalarında Şekil 1.b'deki gibi çelik profiller kullanıldığı için TS EN 13230-3:2016 [45] standardında travers merkezi ile ilgili bu tarz bir deney ve kriter verilmesi söz konusu olmamıştır.

\section{Bulgular}

Çalışma kapsamında, üretimi yapılan travers numunelerine uygulanan, travers merkezinde YKY tipi yüklemelerle negatif eğilme momenti tayini deneyleri sonucunda traverslerin çatlak durumlarını gösterir örnek fotoğraflar Şekil 5-8'de, her numune tipi için örnek test grafikleri ise Şekil 9-12'de sunulmuştur. Şekil 5-8'de travers numuneleri üzerine çatlak işaretlemeleri yapılırken, $\mathrm{Fc}_{0.05}$ yükü altında belirlenen ve yük kaldırıldığında geri kapanarak 0,05 genişliğin altında kalan çatlaklar açık mavi kalemle, bu yük seviyesinin üzerinde ise lacivert kalemle işaretleme yapılmıştır. B70 tipi traversler için; TS EN 13230-2:2016 [44] normuna göre, UIC üyesi ülkelerce şartnamelerde istenen yük tanımları ise toplu olarak Tablo 1'de sunulmuştur.

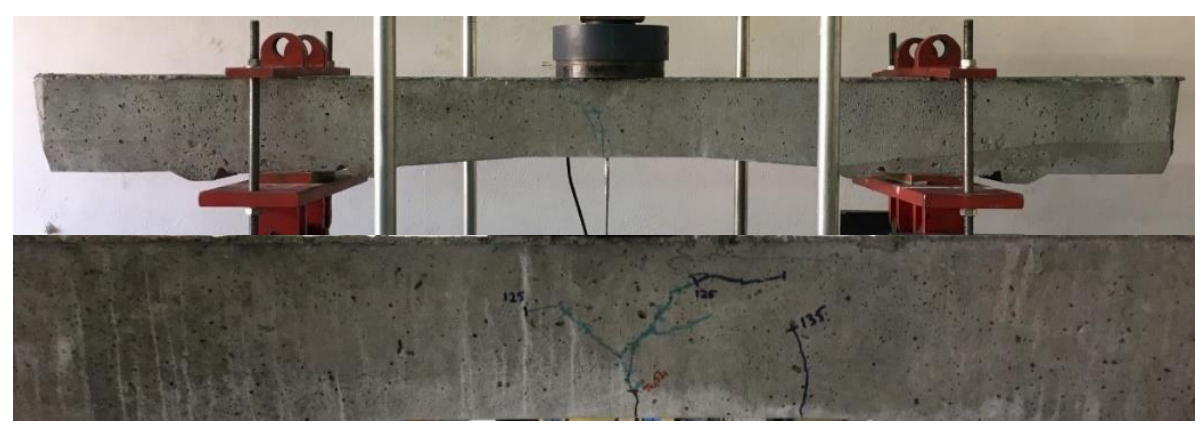

Şekil 5. B70 tipi öngerilmeli beton traversin $135 \mathrm{kN}$ 'luk son yükleme adımı ardından çatlak durumu

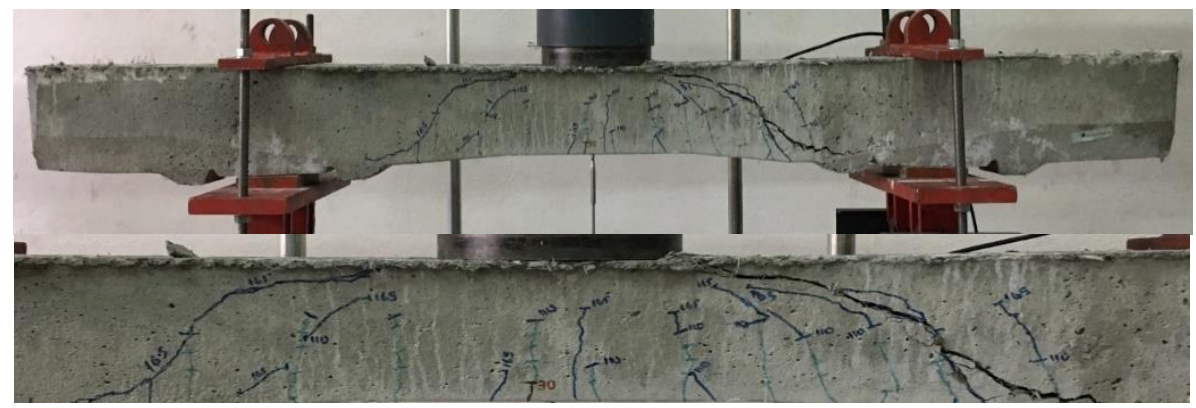

Şekil 6. 22-SND tipi beton traversin 165 kN'luk son yükleme adımı ardından çatlak durumu

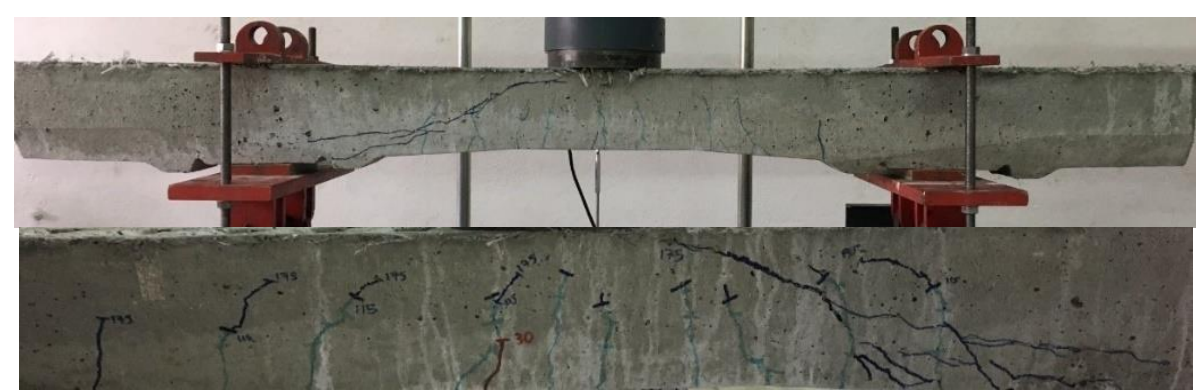

Şekil 7. 30-SND tipi beton traversin 175 kN'luk son yükleme adımı ardından çatlak durumu 


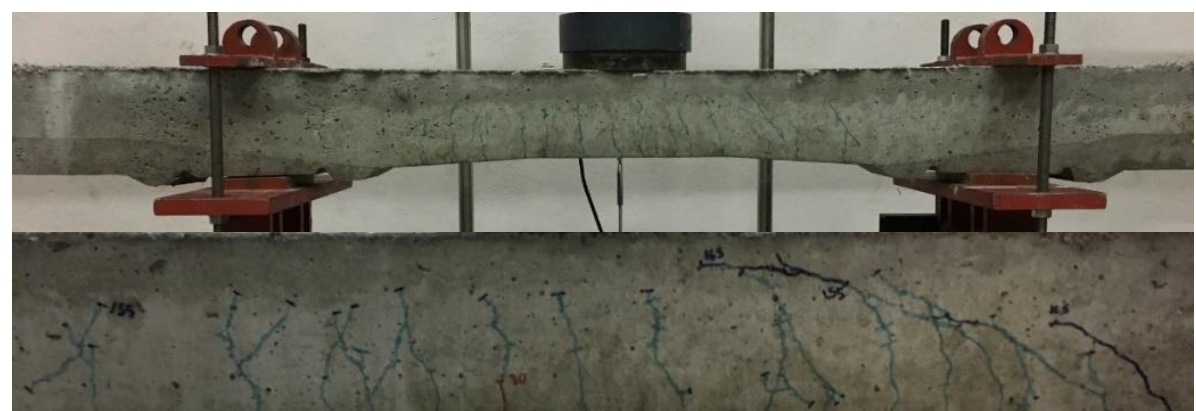

Şekil 8. 30-VRTC-SND tipi beton traversin 170 kN'luk son yükleme adımı ardından çatlak durumu

Tablo 1'de geçen $\mathrm{Fc}_{\mathrm{rn}}(\mathrm{kN})$ değeri için UIC / TCDD şartnamelerinde istenen limit değeri, öngerilmeli traversler içindir. Standartlarda öngerilmesiz traverslerin ilk çatlak başlangıcı ile ilgili olarak, gerek ray mesnedinde, gerekse travers merkezinde herhangi bir limit belirtilmesine gerek görülmemiştir [45, 46]. Şekil 9-12'de ilk çatlak başlangıcı gözlemlenen YKY yük adımı kırmızı, ilk kalıcı çatlak başlangıcı gözlemlenen adım siyah ve zirve yükü gözlemlenen adım ise mavi dolgulu çizgilerle gösterilmiştir. Şekil 9-12'de grafiklerin sağ tarafindaki YKY adım listesinde, 5 kN'luk kademeler halinde artırılan YKY adımlarının sıra numaraları verilmiş olup, ayrıca UIC/TCDD şartnamelerinde istenilen limitlerin belirlendiği adımlarda, bu limitlere ait simgeler eklenmiştir. Örnek olarak Şekil 9'da ilk elastik çatlak belirlenen 1. YKY adımı $\mathrm{Fc}_{\mathrm{rn}}$ simgesiyle, $0,05 \mathrm{~mm}$ kalıcı çatlak belirlenen YKY adımı $\mathrm{Fc}_{0,05}$ simgesiyle, zirve yük belirlenen 10. YKY adımı $\mathrm{Fc}_{\mathrm{bn}}$ simgesiyle, diğer $\mathrm{YKY}$ adımlarından ayrıştırılmıştır. $\mathrm{Fc}_{0,05}$ yükünün standarttaki tanımlamasında istisnai darbe yükü ifadesi kullanılsa da, mevcut standartlarda bu değer YKY testleriyle tahkik edilmektedir. Teste tabi tutulan tüm travers tiplerinin belirlenen dizayn yüklerinin karşılaştırması Şekil 13-15'te verilmiştir.

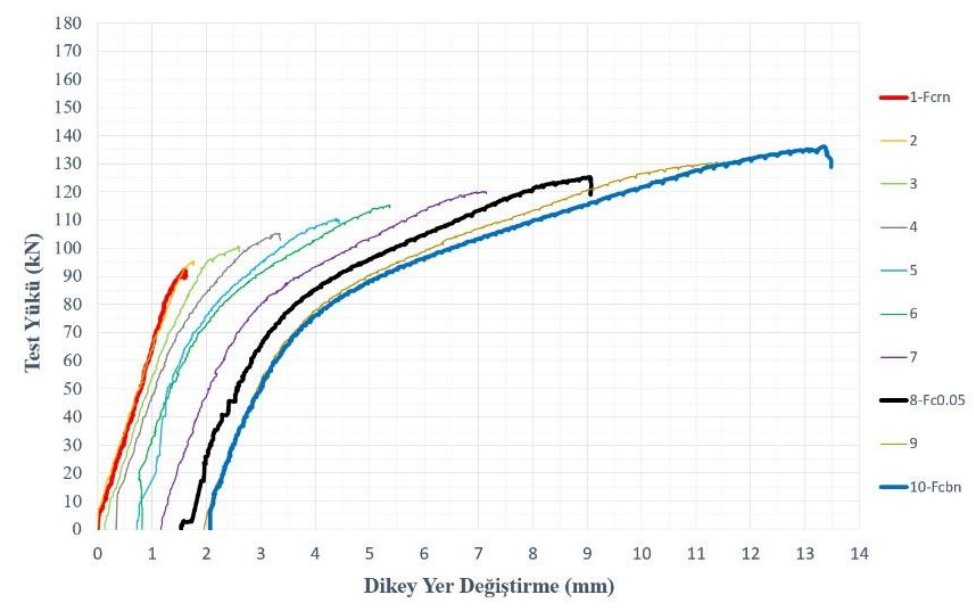

Şekil 9. B70 tipi beton travers numunelerinin örnek test yükü $(\mathrm{kN})$, dikey yer değiştirme $(\mathrm{mm})$ eğrisi 


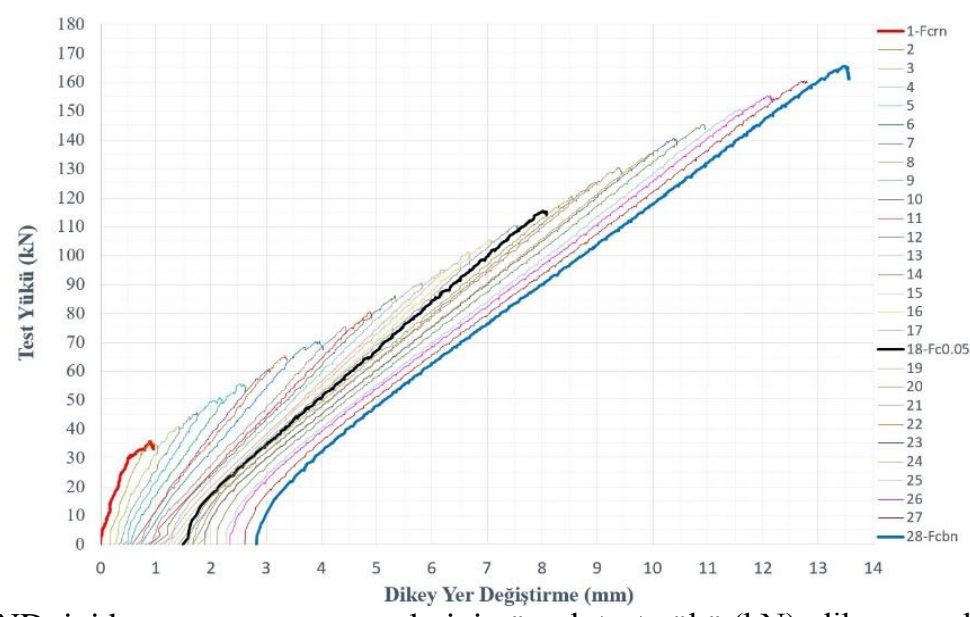

Şekil 10. 22-SND tipi beton travers numunelerinin örnek test yükü $(\mathrm{kN})$, dikey yer değiştirme (mm) eğrisi

Sonuç olarak yapılan tüm bu test ve analizler sonucunda aşağıda belirtilen tespitler yapılmıştır:

1. Teste tabi tutulan tüm L-CFRPU donatılı travers varyasyonların, UIC/TCDD şartnamelerinde istenen dayanım esaslı kriterlerin tamamını sağladığı görülmüştür.

2. Yapılan testler esnasında tüm travers tiplerinde ilk çatlakların kesit ortasındaki dikey eğilme çatlakları ile ortaya çıktığı gözlenmiştir. Artan yük seviyelerinde karşılaştırma numunesi olarak kullanılan ve nervürsüz HTS tipi çelik çubuk donatılar içeren öngerilmeli B70 tipi traverslerdeki çatlakların az sayıda (2-3 adet) ancak yüksek genişlikte meydana geldiği görülmüştür. Kumlamalı L-CFRPU donatılar içeren LCR tipi traverslerde ise çatlak sayısının fazla (>10) fakat genişliklerinin çok az olduğu görülmüştür. LCR tipi traverslerde bu yüzden mesnetlere yakın lokasyonlarda meydana gelen çatlaklar, artan yük seviyelerinde, yük uygulama noktasına doğru uzayarak, eğik çekme çatlakları ve nihayetinde kesme çatlakları meydana gelmiştir. Sonuç olarak karşılaştırma numunelerinde $0,05 \mathrm{~mm}$ üzerindeki kalıcı çatlak tespitine ve kırılma noktasına eğilme çatlakları ile ulaşılırken, LCR tipi traverslerde eğik çekme çatlakları ve kesme çatlakları ile ulaşılmıştır.

3. TS EN 13230-2/3 doğrultusunda yapılan bu 3 noktalı, travers merkezinde negatif moment tayini testlerinde mesnet aralığı 150 santimetre, travers faydalı yüksekliği orta noktada 12,5 santimetredir. Dolayısıyla, kesme açıklığı/derinlik oranı (shear span/effective depth ratio) 6 seviyesinde olduğundan kemerleme (arch action) katkısı ihmal edilebilecek düzeydedir. TS EN 13230-2/3 doğrultusunda yapılan ray mesnedinde pozitif moment tayini deneylerinde ise bu oran (mesnet aralığ 60 santimetre ve travers faydalı yüksekliği 16,4 santimetre ile) 1,8 seviyelerinde olduğundan bu testlerde kemerleme etkisinin katkısı yüksektir. Sonuç olarak daha önceki çalışmalarda ray mesnedinde yapılan testlerde elde edilen üstün dayanım özelliklerinin, kemerleme etkisinden bağımsız olduğu, yeni LCR tipi traverslerin öngerilmesiz ve etriyesiz üretim yöntemine rağmen üstün dayanım sergilediği gözlenmiştir.

4. $0.05 \mathrm{~mm}$ genişliğe sahip ilk kalıcı çatlak tespiti yükü $\left(\mathrm{Fc}_{0.05}\right)$ değerleri karşılaştırıldığında, Şekil 13'te özetlendiği üzere, B70 tipi standart öngerilmeli traversler ile 22-SND ile 30-SND kod numaralı yeni tip traverslerin, UIC kriteri olan $65 \mathrm{kN}$ sınırının çok üzerinde (yaklaşı 120 $\mathrm{kN}$ ) değer verdikleri görülmüştür. 30-VRTC-SND tipi traverslerin ise bu bağlamda yaklaşık \%29 daha yüksek kapasiteye erişerek $155 \mathrm{kN}$ kapasiteye ulaştığı görülmüştür.

5. Zirve kırılma yükü $\left(\mathrm{Fc}_{\mathrm{bn}}\right)$ değerleri karşılaştırıldığında, Şekil 14'te özetlendiği üzere, B70 tipi standart öngerilmeli traverslerin UIC kriteri olan $90 \mathrm{kN}$ sınırının üzerinde ve yaklaşı1k $135 \mathrm{kN}$ değer verdiği görülmüştür. Yeni tip traverslerin tümü, bu değerlerin de üzerinde sonuç vermiş, 22-SND tipi varyasyon ortalama $165 \mathrm{kN}$, 30-VRTC-SND tipi varyasyon $170 \mathrm{kN}$ ve 30-SND tipi varyasyon ise $175 \mathrm{kN}$ yüke kadar mukavemet göstermiştir. 
6. Yapılan testler esnasında, B70 tipi öngerilmeli traverslerin ilk çatlak başlangıç yükü olan 90 kN değerinin, her YKY adımı ardından düştüğü gözlenmiştir. Bu traversler için Şekil 9'da örneği sunulan test grafiğinde de görüleceği üzere, YKY basamaklarına ait (betonda çatlamalara işaret eden) eğrilerin eğimlerinin değiştiği büküm noktaları, her YKY adımında daha da erken bir yük seviyesine düşmektedir. Fiziki gözlemler ve grafik analizleriyle tespit edildiği üzere, bu değer nihai olarak $50 \mathrm{kN}$ mertebesine kadar düşmektedir. Bu tespit TS EN 13230-2-6 [44, 46] standartlarında yorulma esaslı dizayn yükünün neden ilk çatlak başlangıç yükü olan $\mathrm{Fc}_{\mathrm{rn}}$ değeri değil de bundan daha düşük bir değer olarak Tablo 1'de de verilen; en az $35 \mathrm{kN}$ 'luk $\mathrm{Fc}_{\mathrm{on}_{\mathrm{n}}}$ değerinin esas alınmasını izah etmektedir. Dolayısıyla teste tabi tutulan B70 tipi traversler için yorulma esaslı dizayn yükü $\left(\mathrm{Fc}_{\mathrm{on}}\right) 50 \mathrm{kN}$ olarak belirlenmiştir.

7. TS EN 13230-3-6 [45, 46] standartlarında belirtilen kriterler ve UIC üyesi Demiryolu Kuruluşlarınca hazırlanan Teknik Şartnameler baz alındığında; Tablo 1'de ve Şekil 15 'te özetlendiği üzere, yeni tip traverslerin yorulma esaslı dizayn yükü 0,05 mm'lik kalıcı çatlak başlangıcı yüküne $\left(\mathrm{Fc}_{0.05}\right)$ tekabül eden $120-155 \mathrm{kN}$ düzeylerinde olduğu gözlenmiştir. Traverslerin servis dizayn yükleri belirlenirken elde edilen bu değerler, sıradan tek kademeli statik eğilme testleriyle değil, her bir numune için birkaç saat süren 5 kN'luk basamaklar halinde artan yükleme-kaldırma-tekrar yükleme çevrimli (YKY) özel testler ile belirlenmiştir. Test grafikleri incelendiğinde yeni tip traverslerin 30 basamağa ulaşan YKY çevrimine tabi tutulduğu görülmektedir. Bununla birlikte, kesin sonuçlara TS EN 13230-2-3 [44, 45] doğrultusunda yapılacak yorulma testleri ile ulaşılabilecektir.

8. Şekil 9-12 incelendiğinde, yeni tip traverslerde herhangi bir öngerilme kuvveti veya etriye/spiral donatı kullanılmamasına rağmen, meydana gelen kalıcı deformasyon düzeyleri incelendiğinde, öngerilmeli B70 tipi traverslerle benzer plastik deformasyonlar söz konusu olduğu görülmektedir. Giriş bölümünde belirtildiği üzere, traverslerin tekrarlı yükler etkisinde plastik deformasyon düzeylerinin kısttlanması, raylı sistemlerde ekartman açıklıklarının korunması ve travers servis ömrünün artırılması adına oldukça önemlidir. $\mathrm{Bu}$ bağlamda, özellikle 30-VRTC-SND tipi travers modeli büyük avantaja sahip olup, 25 adımlık YKY yükleme basamağı ardından ve B70 tipi öngerilmeli traverslerin kırılma yükünün üzerindeki 155 kN'luk yük değerine kadar, traversteki meydana gelen çatlak genişlikleri halen 0,05 mm'nin altında kalmıştır. Şekil 8 'den de görülebileceği üzere bu performansını, zirve yüküne ulaşmasına rağmen büyük oranda sürdürmüştür.

Tablo 1. Travers merkezlerinde YKY tipi test sonuçlarının ve şartname limitlerinin karşılaştırması

\begin{tabular}{ccccc}
\hline Numune Tanımı & $\mathrm{Fc}_{\mathrm{rn}}(\mathrm{kN})$ & $\mathrm{Fc}_{0,05}(\mathrm{kN})$ & $\mathrm{Fc}_{\mathrm{bn}}(\mathrm{kN})$ & $\mathrm{Fc}_{\mathrm{on}}$ \\
\hline B70 Standart & 90 & 125 & $135(\mathrm{Baz})$ & 50 \\
22-SND & 35 & 115 & 165 & 115 \\
30-SND & 30 & 120 & 175 & 120 \\
30-VRTC-SND & 30 & 155 & 170 & 155 \\
UIC / TCDD Şartname Limiti & $>35$ & $>65$ & $>90$ & 35 \\
\hline
\end{tabular}




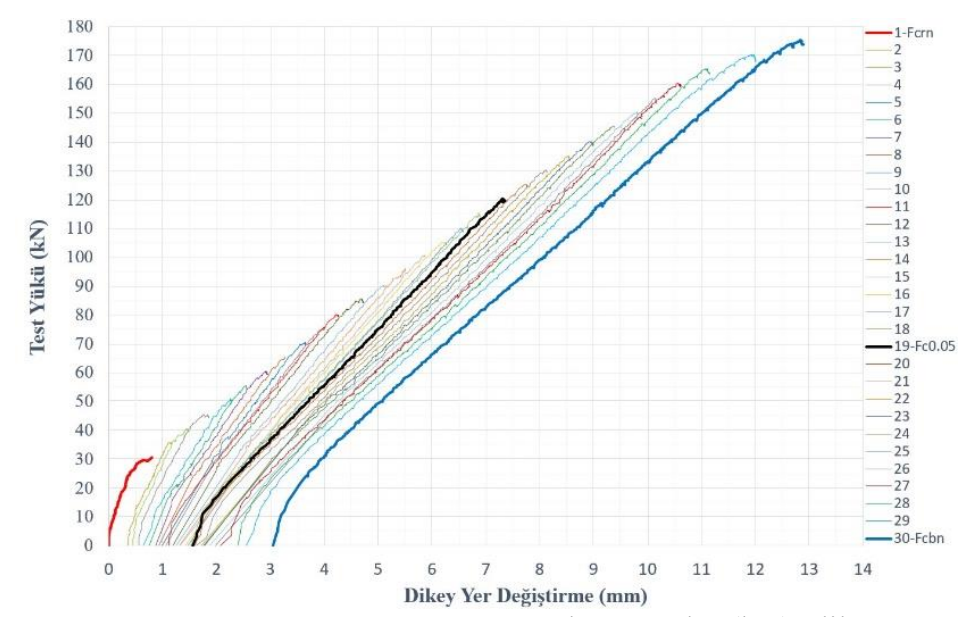

Şekil 11. 30-SND tipi beton travers numunelerinin örnek test yükü $(\mathrm{kN})$, dikey yer değiştirme (mm) eğrisi

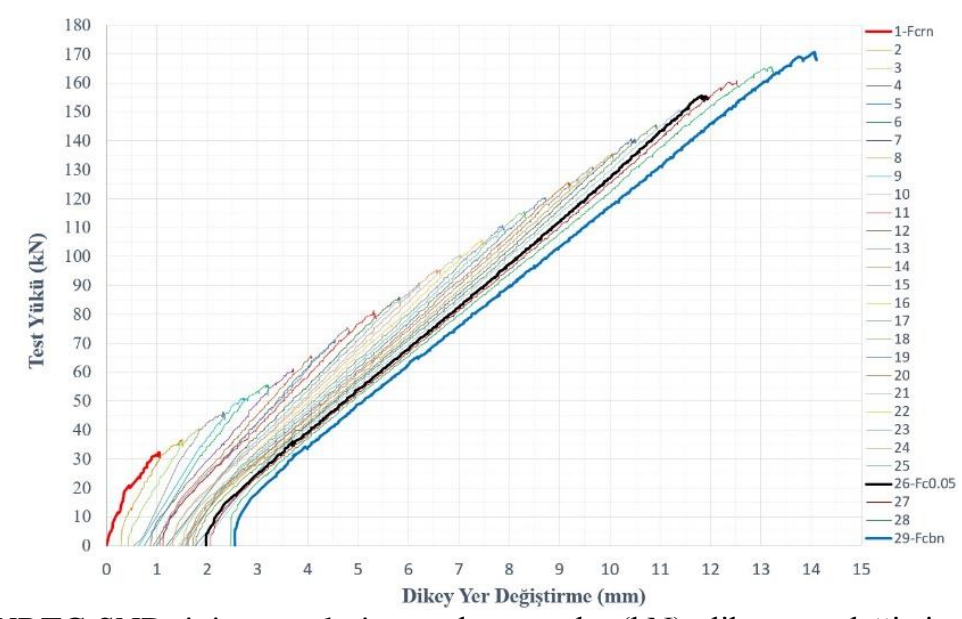

Şekil 12. 30-VRTC-SND tipi traverslerin örnek test yükü $(\mathrm{kN})$, dikey yer değiştirme $(\mathrm{mm})$ eğrisi

\section{Sonuç}

Günümüzde tüm dünyada balastlı demiryolu hatlarında en yaygın olarak kullanılan öngerilmeli beton traverslerin birçok avantajı söz konusu olmasına rağmen, günümüzün işletim koşulları altında bu traverslerin birçoğu planlanan 40-50 yıllık dizayn ömrüne ulaşamadan değiştirilmek zorunda kalmaktadır. Bu durum, tüm dünyada demiryolu bakım işlemlerinin maliyetini artırmaktadır. Ayrıca modern demiryolu işletmeciliğinde, tren seferleri çok sık aralıklarla yapıldığından, bakım ve tamirat işlemleri için ayrılabilecek süreler, geceleri birkaç saatle kısıtlıdır. Bunların dışında, Ülkemiz için söz konusu olan bir diğer unsur, öngerilmeli beton travers üretiminde kullanılan HTS tipi çelik öngerilme çubuklarının çoğunlukla ithal edilmesidir. $\mathrm{Bu}$ çalışmada, dünyada mevcut beton traverslerde kullanılan çelik donatılar yerine, yerli lamine karbon fiber takviyeli poliüretan plakalar (L-CFRPU) inovatif bir şekilde, uygun ebatlarda kesilerek ve kumlama yapılarak, beton donatısı olarak kullanılmıştır. 


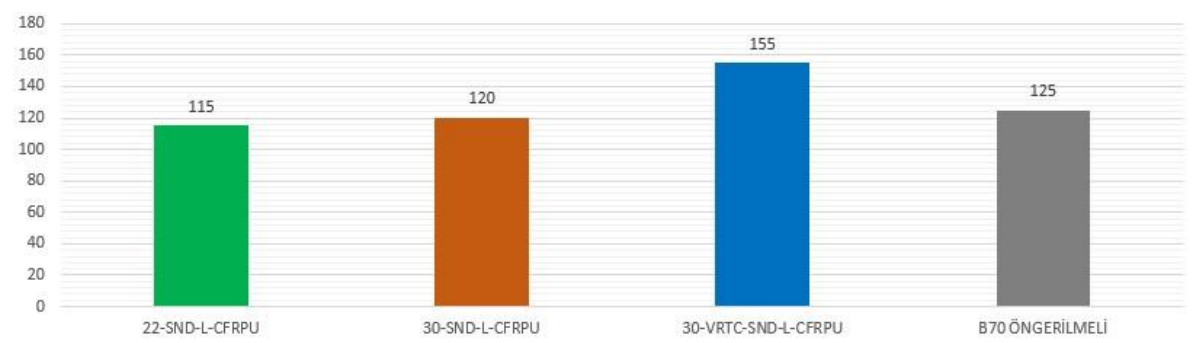

Şekil 13. Teste tabi tutulan traverslerin 0.05 mm'lik kalıcı çatlak başlangıcı yükü $\left(\mathrm{Fc}_{0.05}\right)$ karşılaştırması

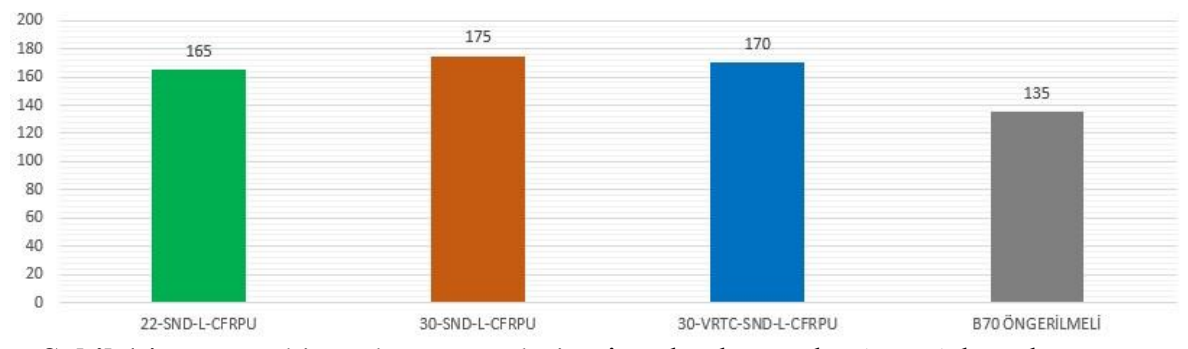

Şekil 14. Teste tabi tutulan traverslerin zirve kırılma yükü ( $\left.\mathrm{Fc}_{\mathrm{b} n}\right)$ karşılaştırması

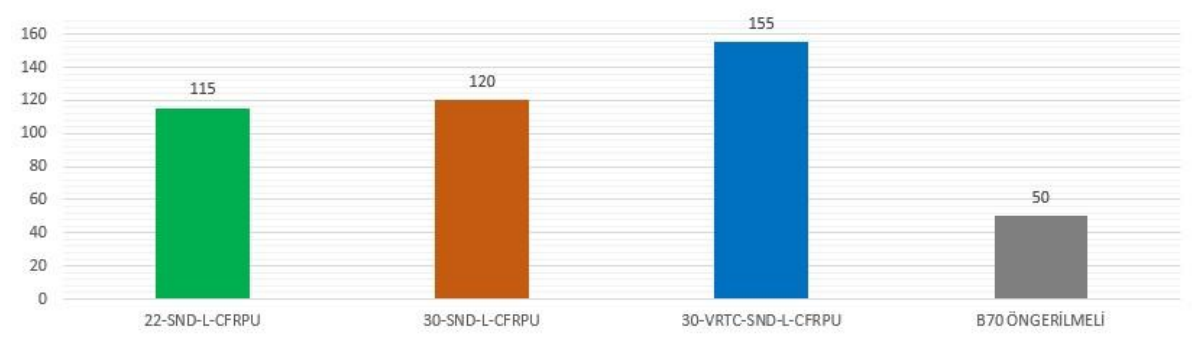

Şekil 15. Teste tabi tutulan traverslerin yorulma esaslı servis dizayn yükü ( $\mathrm{Fc}_{\text {o n }}$ ) karşılaştırması

Bu yeni tip traversler, geçtiğimiz yıllarda çeşitli testlere tabi tutulmuş ve yapılan test ve analiz sonuçlarına göre, yeni tip traverslerin dünyada mevcut diğer travers tiplerine göre $\% 180$ 'e varan oranda daha yüksek kalıcı çatlak başlangıç yükü kapasitesine ve \%128'e varan oranda daha yüksek kırılma yükü kapasitesine eriştiği ve $\% 58$ daha yüksek sönümleme performansı sergilediği görülmüştür. Yeni tip traversler, bu avantajlarının yanı sıra, öngerilmesiz ve etriyesiz pratik üretim yöntemi sayesinde, büyük bir üretim kolaylığ 1 ve ekonomisi de vadetmektedir. Kullanılan karbon fiber malzemeler, dünyada yalnızca 9-10 ülkede üretilebilmekte olup, bunlardan biri Türkiye'dir ve yeni tip traverslerde kullanılacak karbon-fiber donatıların maliyeti, mevcut öngerilmeli travers donatılarına göre \%23'e varan oranda daha düşük maliyetlidir. Bu maliyet avantajı, yeni tip traverslerin öngerilmesiz ve etriyesiz kolay üretim şekliyle daha da artmaktadır. Yeni tip traverslerin, fiili servis ömründe sağlayacağı artış ve demiryolu bakım ve işletim işlemlerinde sağlanacak tasarruflar ile mali avantajı kat kat artmaktadır. Günümüzde dünya genelinde en az 3 milyar travers kullanılmakta olup, bunların ise her yıl en az 150 milyon adedi erken deformasyonlar nedeniyle değiştirilmek zorunda kalmaktadır. Dolayısıyla yeni tip traverslerin yüksek ticarileşme potansiyeli bulunmaktadır ve hitap ettiği pazarın market hacmi oldukça büyüktür.

Çalı̧̧ma kapsamında yeni tip traverslerin bugüne değin incelenmemiş bir özelliği, öngerilmeli B70 tipi traverslerle karşılaştırmalı yürütülen deneyler ile araştırılmıştır. Yeni tip traverslere uygulanan travers merkezinde negatif moment tayini testleri akabinde, teste tabi tutulan tüm varyasyonların, UIC/TCDD şartnamelerinde beton traverslerden istenen kriterlerin tamamını sağladığı görülmüştür. Ayrıca yeni tip traverslerin $0.05 \mathrm{~mm}$ genişliğe sahip ilk kalıcı çatlak tespiti yükü bakımından \%29'a varan oranda daha yüksek kapasiteye erişilebildiği, bu başarının kırılma 
yükü kapasitesi açısından da sağlandığı görülmüş̧tür. Yorulma esaslı dizayn yükü bakımından ise, B70 tipi öngerilmeli traverslerin 2 katına ulaşan oranda daha yüksek sonuçlar alınmıştır. Uygulanan ağır şartlara sahip yükleme-kaldırma-yeniden yükleme esaslı testlerle belirlenen bu yüksek potansiyelin, dinamik ve yorulma testleriyle de teyit edilmesi gerekmektedir. Yapilan testler sonucunda ulaşılan bir diğer önemli avantaj, yeni tip traverslerde herhangi bir öngerilme kuvveti veya etriye/spiral donatı kullanılmamasına rağmen, meydana gelen kalıcı deformasyon düzeylerinin, öngerilmeli B70 tipi traverslerle benzer başarı sağladığı, hatta B70 tipi öngerilmeli traverslerin kırılma yükünün üzerindeki yük değerlerinde dahi, yeni tip traverslerde meydana gelen çatlak genişliklerinin halen 0,05 mm'nin altında kaldığ 1 görülmüştür. Bu avantaj raylı sistemlerde ekartman açıklıklarının korunarak deray ve kazaların önlenmesi ve travers servis ömrünün artırılması adına oldukça önemlidir.

\section{Teşekkür}

Bu çalışma, Tübitak Ardeb Dairesi Başkanlığı'nın 120M403/2020 sayılı projesi kapsamında desteklenmektedir. Ayrıca katkılarından dolayı TCDD Sivas Beton Travers Fabrikası Müdürü Sn. Ali KARABEY'e ve dowAksa ${ }^{\circledR}$ firması yetkilisi Sn. Ilgaz DOĞAN'a teşekkürlerimizi bildiririz.

\section{Kaynakça}

[1] F. Çeçen, B. Aktaş, "Yeni nesil demiryolu traversleri ve yerli frp donatı kullanımının deneysel araştırması," Demiryolu Mühendisliği, Ocak 2021, Sayı: 13, Sayfa: 53-64. doi: https://doi.org/10.47072/demiryolu.803452

[2] J. Taherinezhad, M. Sofi, P. A. Mendis, T. A. Ngo, "Review of behaviour of prestressed concrete sleepers," Electronic Journal of Structural Engineering, 2013, vol: 13(1), pp: 1-16

[3] F. Çeçen, B. Aktaş, "Modal and harmonic response analysis of new cfrp laminate reinforced concrete railway sleepers," Engineering Failure Analysis, Vol: 127, no 105471, doi: https://doi.org/10.1016/j.engfailanal.2021.105471

[4] C. Esveld, Modern railway track. ISBN 978-1-326-05172-3, 2014

[5] S. Li, "Railway sleeper modelling with deterministic and non-deterministic support conditions," Division of Highway and Railway Engineering Department of Transport Science, School of Architecture and the Built Environment, Royal Institute of Technology, Stockholm, 2012

[6] Z. Öztürk, V. Arl, Demiryolu mühendisliği. ISBN 978-605-60958, 2009

[7] M. S. Çelik, Z. Öztürk, "Demiryolu traverslerinin çok yönlü incelenmesi ve örnek hat üzerinde kullanılan farklı tipteki traverslerin irdelenmesi," Yüksek lisans tezi, İstanbul Teknik Üniversitesi, Fen Bilimleri Enstitüsü, İnşaat Mühendisliği ABD, Ulaştırma Mühendisliği Programı, İstanbul, 2015

[8] J. C. Bastos, "Analysis of the performance and failure of railroad concrete crossties with various track support conditions," Master thesis, Graduate College of the University of Illinois, Urbana, 2016

[9] F. Çeçen, "Carbon fiber reinforced polymer (CFRP) reinforced concrete railway sleepers," Master Thesis, Gazi Osman Paşa University, Graduate School of Natural and Applied Sciences, 156 pages, Tokat. doi: https://doi.org/10.13140/RG.2.2.22723.430492019

[10]P. Mendis, "Design of high-strength concrete members, state-of-the-art," Progress in Structural Engineering and Materials, 2003, vol. 5 (1), pp. 1-15

[11] A. Remennikov, S. Kaewunruen, "Investigation of vibration characteristics of prestressed concrete sleepers in free-free and in-situ conditions," 2005. [Online]. Available (25.11.2021): http://ro.uow.edu.au/engpapers/284

[12] H. P. J. Taylor, "The railway sleeper: 50 years of pretensioned, prestressed concrete," 1993. [Online]. Available

(15.09.2021): https://www.researchgate.net/publication/288948138_The_prestressed_concrete_railway_sleepers_50_years_of_pretensioned_prestressed_concrete

[13] USA ACI-ASCE Committee 423, ACI 423.5R-99: State-of-the-art report on partially prestressed concrete, $2017 . \quad$ [Online]. Available https://www.concrete.org/store/productdetail.aspx?ItemID=423599\&Format=DOWNLOAD\&Langu age $=$ English \&Units $=$ US_Units

[14] A. Jokūbaitıs, J. Valıvonıs, G. Marčiukaitıs, "Analysis of strain state and cracking of concrete sleepers.” Journal Of Civil Engineering And Management, Vol. 22(4), pp. 564-572, 2016 
[15] W. Ferdous, A. Manalo, G. V. Erp, T. Aravinthan, S. Kaewunruen, A. M. Remennikov, "Composite railway sleepers - recent developments, challenges and future prospects," Composite Structures, 2015, Vol: 134 (2015), pp. 158-168, doi: https://doi.org/10.1016/j.compstruct.2015.08.058

[16] J. Sýkorová, J. Bártová, P. Štemberk, "Prestressed concrete sleeper under extreme loading conditions," 18th International Conference Engineering Mechanics, Svratka, Czech Republic, May 14 - 17, 2012.

[17] R. You, D. Li, C. Ngamkhanong, S. Kaewunruen, "Fatigue life assessment method for prestressed concrete sleepers," Frontiers in Built Environment, 2017, Volume 3, Article 68

[18]N. Ö. Bezgin, “Öngerilmeli beton traverslerde gözlenen zamana bağlı kısalmalarının değerlendirilmesi,” Demiryolu Mühendisliği, 2018, Vol: 9, pp. 17-27

[19] N. Ö. Bezgin, "An insight into design of prefabricated and prestressed concrete monoblock railway ties for service loads," Challenge Journal Of Structural Mechanics, 2018, Vol: 4, pp. 126-136

[20] S. Kaewunruen, "Experimental and numerical studies for evaluating dynamic behaviour of prestressed concrete sleepers subject to severe impact loading," Doctor of philosophy thesis, Univeristy of Wollongong, New South Wales, Australia, 2007

[21]H. E. Wolf, "Flexural Behavior Of Prestressed Concrete Monoblock Crossties,"'Master of Science Thesis, Graduate College of the University of Illinois, Civil Engineering, Urbana, 2015

[22] A. M. Guðmundsson, "Prestress losses in railway sleeper production with long bed systems," Master of Science Thesis, Chalmers Unıversity Of Technology, Göteborg, Sweden, 2014.

[23] A. M. Remennikov, M. H. Murray, S. Kaewunruen, "Conversion of AS1085.14 for prestressed concrete sleeepers to limit states design format," Proceeding of AusRAIL PLUS, Australia, 2007.

[24] J. Leong, M. H. Murray, "Probabilistic analysis of train-track vertical impact forces," Proceedings of the ICE - Transport, 2008, Vol: 161 (1), pp. 15-21.

[25] J. Nairn, N. Stevens, "Rational design method for prestressed concrete sleepers," in Conference on Railway Engineering, Wellington, Australia, 2010, pp. 174-190

[26]B. J. Van Dyk, M. S. Dersch, J. R. Edwards, "Technical report," RailTEC, UIUC International Concrete Crosstie and Fastening System Survey, USA, 2012

[27] H. Thun, H. Utsi, L. Elfgren, "Load carrying capacity of cracked concrete railway sleepers," Structural Concrete, 2008, Vol: 9 (3), pp. 153-161

[28] W. Ferdous, A. Manalo,. "Failures of mainline railway sleepers and suggested remedies -review of current practice," Engineering Failure Analysis, 2014, Vol. 44, pp. 17-35

[29] S. Kaewunruen, D. Li, Y. Chen, Z. Xiang, "Enhancement of dynamic damping in eco-friendly railway concrete sleepers using waste-tyre crumb rubber," MDPI Materials, 2018, vol. 11 (7), ID 1169

[30]R. You, S. Kaewunruen, "Evaluation of remaining fatigue life of concrete sleeper based on field loading conditions," Engineering Failure Analysis, 2019, vol. 105, pp. 70-86

[31] S. Kaewunruen, A. M. Remennikov, "Impact capacity of railway prestressed concrete sleepers," Engineering Failure Analysis, 2009. vol. 16 (5), pp. 1520-1532

[32] S. Mohammadzadeh, E. Vahabi, "Time-dependent reliability analysis of B70 pre-stressed concrete sleeper subject to deterioration," Engineering Failure Analysis, 2011, vol. 18(1), pp. 421-432

[33] S. Li, "Railway sleeper modelling with deterministic and non-deterministic support conditions," Master Degree Project, Royal Institute of Technology, Stockholm, 2012

[34] M. H. Murray, J. Bian, "Ultimate limit states design of concrete railway sleepers," Proceedings of the Institution of Civil Engineers, August 2012, Issue TR3, Pages 215-223

[35] A. M .Remennikov, M. H. Murray, S. Kaewunruen, "Dynamic design guidelines for prestressed concrete sleepers," 2008. [Online]. Available (25.11.2021): https://ro.uow.edu.au/engpapers/492/

[36] R. Fico, "Limit states design of concrete structures reinforced with frp bars," PH. D. Thesis, University Of Naples Federico II, Materials And Structures Engineering, 2008

[37] K. Brózda, J. Selejdak, P. Koteš, "Analysis of the crack width of beams reinforced with FRP bars," Technical Transactions/Mechanics, 2018, Vol. 11, pp. 163-168

[38]F. Çeçen, B. Aktaş, "Lamine cfrp donatılı traverslerin deneysel ve sonlu eleman analizleriyle incelenmesi," Demiryolu Mühendisliği, 2021, vol: 14, pp: 26-38. doi: https://doi.org/10.47072/demiryolu.869946

[39]F. Çeçen, B. Aktaş, “Incremental LUR Tests of New LCR Concrete Railway Sleepers,” Engineering Failure Analysis, 2021, vol: 130, ID: 105793, doi: https://doi.org/10.1016/j.engfailanal.2021.105793

[40] B. Aktaş, F. Çeçen, H. Öztürk, M. B. Navdar, İ. Ş. Öztürk, "Comparison of prestressed concrete railway sleepers and new LCR concrete sleepers with experimental modal analysis," Engineering Failure Analysis, 2022, vol. 131, ID: 105821, doi: https://doi.org/10.1016/j.engfailanal.2021.105821

[41] Sleeper technology, [Online]. Available (25.11.2021): https://www.p-tec.org/en/sleeper-technology/ 
[42] ITB-Tradetech,

[Online].

Available

(25.11.2021):

https://www.railwaytechnology.com/contractors/rail/itb-tradetech/

[43]Leeds Live, [Online]. Available (25.11.2021): https://www.leeds-live.co.uk/news/leedsnews/gallery/leeds-train-station-platform-zero-17493047

[44] Demiryolu uygulamalarl - Demiryolu - Beton traversler ve mesnetler- Bölüm 2:Öngerilmeli yekpare traversler, TS EN 13230-2:2016, Türk Standartları Enstitüsü, Ankara, 2016

[45] Demiryolu uygulamaları - Yol - Beton traversler ve mesnetler - Bölüm 3: Donatıl ikiz traversler, TS EN 13230-3:2016, Türk Standartları Enstitüsü, Ankara, 2016

[46] Demiryolu uygulamalar - Hat - Beton traversler ve taşıyıcılar - Bölüm 6: Tasarım, TS EN 132306:2020, Türk Standartları Enstitüsü, Ankara, 2020
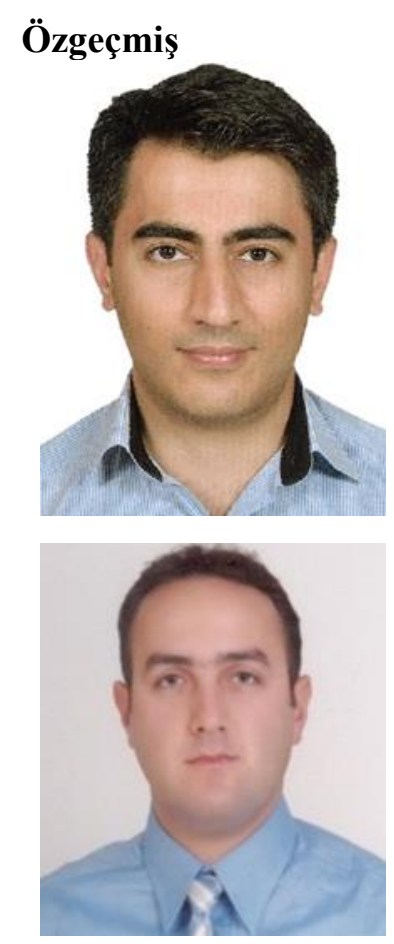

\section{Ferhat ÇEÇEN}

TCDD Sivas Beton Travers Fabrikası'nda Üretim Grup Müdürlüğü görevini yürütmekte olan yazar, Erciyes Üniversitesi'nde Ulaştırma alanında doktora eğitimine devam etmektedir. Yerli ileri fonksiyonel malzemelerle milli demiryolu traversleri geliştirilmesi amaçlı ar-ge çalışmaları devam etmektedir.

E-Posta: ferhatcecen@tcdd.gov.tr

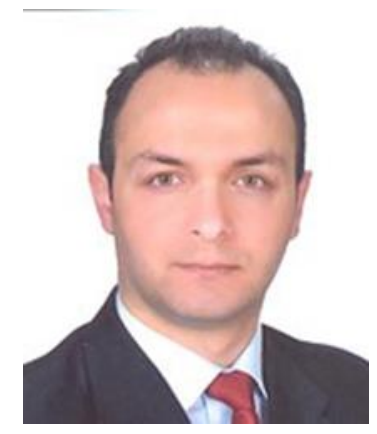

\section{Bekir AKTAŞ}

Doktora Eğitimini Süleyman Demirel Üniversitesinde tamamlayan yazar, Erciyes Üniversitesi İnşaat Mühendisliği Bölümü Ulaştırma Anabilim Dalında öğretim üyesidir. Ulaştırma alanında yerli ve yabancı dergilerde yayımlanan birçok makalesi bulunmaktadır. E-Posta: baktas@erciyes.edu.tr

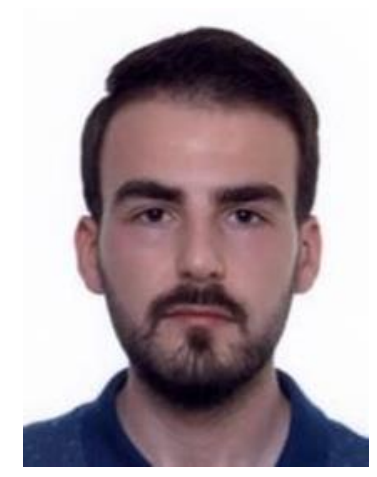

\section{Hakan ÖZTÜRK}

Doktora Eğitimini Sakarya Üniversitesinde tamamlayan yazar, Sakarya Üniversitesi İnşaat Mühendisliği Bölümü Yap1 Anabilim Dalında öğretim üyesidir. Yapı alanında yerli ve yabancı dergilerde yayımlanan makaleleri bulunmaktadır.

E-Posta: hakanozturk@sakarya.edu.tr

\section{İrfan Ş. ÖZTÜRK}

Doktora Eğitimine Sakarya Üniversitesinde devam etmekte olan yazar, Sakarya Üniversitesi İnşaat Mühendisliği Bölümü Yap1 Malzemesi Anabilim Dalında öğretim elemanı olarak görev yapmaktadır.

E-Posta: sehrullahozturk@sakarya.edu.tr 


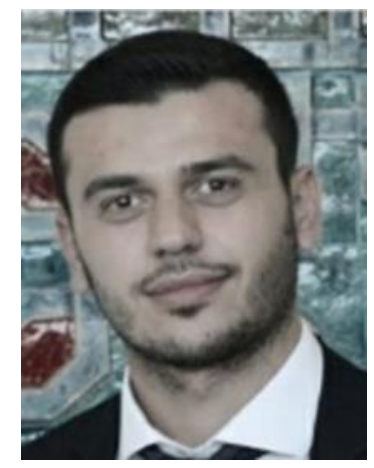

M. Burhan NAVDAR

1993 yılında Rize'de doğmuştur. Lisans eğitimini Yıldız Teknik Üniversitesinde, yüksek lisans eğitimini Sakarya Üniversitesinde tamamlayan yazar, Sakarya Üniversitesi İnşaat Mühendisliği Bölümü Yapı Anabilim Dalında ögrretim elemanı olarak görev yapmaktadır. E-Posta: navdar@sakarya.edu.tr

\section{Beyanlar:}

Bu makalede bilimsel araştırma ve yayın etiğine uyulmuştur.

Yazarların katkıları: Tüm yazarların eşit katkısı olmuştur. 